\title{
SEBARAN KANDUNGAN OKSIGEN TERLARUT PERAIRAN PANTAI SEBAGAI DAYA DUKUNG USAHA TAMBAK DI KABUPATEN JEPARA
}

\author{
Arif Mustofa \\ Fakultas Sains dan Teknologi UNISNU Jepara \\ arifmustofa@unisnu.ac.id
}

\begin{abstract}
Jepara Regency has a coastal area which has the potential to develop aquaculture. The aquaculture business relies on sea water as a culture medium so that it requires information on sea water quality parameters. One important parameter of seawater quality is dissolved oxygen (DO). Because aquatic creatures depend heavily on oxygen for their life and growth. This study aims to provide information about the parameters of dissolved oxygen along the coast of Jepara Regency to support aquaculture ponds. The study used a survey method by measuring parameters of dissolved oxygen levels and seawater temperatures throughout Jepara Regency. There are 10 observation points with distance between $700 \mathrm{~m}$ and distance from coast about $500 \mathrm{~m}$. Repetition is done 3 times around the observation point. Analysis is done qualitatively to get conclusions. The results showed that DO content ranged from $4.7 \mathrm{mg} \mathrm{I}-5.4 \mathrm{mg} / \mathrm{l}$ and temperatures ranged from $27.8^{\circ} \mathrm{C}-28.6^{\circ} \mathrm{C}$. The lowest $D O$ is in the coastal waters of Mororejo Village, Mlonggo District and the highest is in the coastal waters of Keling District. Based on the analysis of DO content along the coast waters of Jepara Regency, the waters of the Kedung, Tahunan, Kembang, Keling and Donorojo Districts have DO levels between $5.1 \mathrm{mg} / \mathrm{l}-5.4 \mathrm{mg} / \mathrm{l}$. This value indicates that the class is suitable for supporting pond aquaculture activities.
\end{abstract}

Keywords: DO, Jepara, ponds, sea, oxygen

\begin{abstract}
Abstrak
Kabupaten Jepara memiliki wilayah pesisir sangat berpotensi untuk pengembangan perikanan budidaya. Usaha budidaya perairan mengandalkan air laut sebagai media budidaya sehingga sangat memerlukan informasi parameter kualitas air laut. Salah satu parameter kualitas air laut yang penting adalah kadar oksigen terlarut (DO). Karena makhluk air sangat bergantung pada oksigen untuk hidup dan pertumbuhannya. Penelitian ini bertujuan untuk memberikan informasi tentang parameter oksigen terlarut di sepanjang pantai Kabupaten Jepara guna mendukung budidaya tambak. Penelitian menggunakan metoda survei dengan melakukan pengukuran paramater kadar oksigen terlarut dan suhu air laut di sepanjang Kabupaten Jepara. Titik pengamatan sebanyak 10 buah dengan jarak antar titik sepanjang $700 \mathrm{~m}$ dan jarak dari pantai sekitar $500 \mathrm{~m}$. Pengulangan dilakukan sebanyak 3 kali di sekitar titik pengamatan. Analisa dilakukan secara kualitatif untuk mendapatkan kesimpulan. Hasil penelitian menunjukkan bahwa kandungan DO berkisar antara 4,7 mg/l $-5,4 \mathrm{mg} / \mathrm{l}$ dan suhu berkisar antara $27,8^{\circ} \mathrm{C}-28,6^{\circ} \mathrm{C}$. DO terendah berada di perairan pantai Desa Mororejo Kecamatan Mlonggo dan tertinggi di perairan pantai Kecamatan Keling. Berdasarkan analisa kandungan DO di sepanjang perairan pantai Kabupaten Jepara, perairan pantai Kecamatan Kedung, Tahunan, Kembang, Keling dan Donorojo memiliki kadar DO antara 5,1 mg/l - 5,4 mg/l. Nilai ini menunjukkan kelas sesuai untuk mendukung kegiatan budidaya tambak.
\end{abstract}

Kata kunci: DO, Jepara, tambak, laut, oksigen

\section{PENDAHULUAN}

Keberhasilan usaha tambak tidak lepas dari tersedianya kualitas air yang optimal. Faktor pendukung kuaitas air berupa parameter kimia, fisika dan biologi oseanografi harus benar-benar diukur untuk mendapatkan data yang menunjang dalam perancangan sebuah usaha budidaya tambak. Karena kualitas air mempengaruhi kegiatan usaha budidaya sejak tahap awal hingga pra-panen. 
(Aliyah, 2013). Salah satu faktor penting sebagai pendukung untuk diperhatikan adalah kadar oksigen terlarut (Dissolved Oxygen/DO) dalam perairan. Karena oksigen sangat penting bagi makhluk hidup untuk melangsungkan kehidupannya. Menurut Boyd (1982) kandungan DO dalam perairan berubah-ubah dipengaruhi oleh beberapa faktor yaitu suhu, salinitas, turbulensi air dan tekanan atmosfer. Kebutuhan oksigen hewan air berbeda tergantung pada jenisnya. Faktor yang mempengaruhi kebutuhan osigen hewan air dipengaruhi oleh suhu, $\mathrm{CO}_{2}, \mathrm{pH}$, dan kecepatan metabolik tubuh. Semakin meningkat suhu perairan maka kebutuhan oksigen semakin besar. Sedangkan ukuran tubuh berkaitan aktivitasnya yang berpengaruh terhadap proses respirasi, semakin besar tubuhnya kebutuhan oksigen semakin rendah.

Baku mutu air sesuai dengan PP No. 82 Tahun 2001, di mana klasifikasi mutu pada kelas dua yang peruntukannya untuk pembudidayaan disebutkan angka batas minimun untuk oksigen terlarut adalah $4 \mathrm{mg} / \mathrm{l}$. Menurut Wardoyo (1981) menjelaskan bahwa pada suhu $25^{\circ} \mathrm{C}$ di perairan air tawar kadar DO pada nilai $8 \mathrm{mg} / \mathrm{l}$ dan di perairan laut 7 $\mathrm{mg} / \mathrm{l}$. Kadar DO maksimum terjadi pada sore hari dan akan kekurangan pada pagi hari. Hal ini dipengaruhi oleh berkurangnya difusi oksgen dari atmosfer, dekomposisi bakteri pada malam hari sebelumnya juga dipengaruhi oleh aktivitas respirasi tumbuhan air. (Odum, 1971).

Kabupaten Jepara memiliki wilayah pertambakan yang dikelola oleh masyarakat di sepanjang pantai seluas 909,63 $\mathrm{km}^{2}$. (Mardiatno dkk., 2018). Produksi perikanan budidaya secara umum mengalami peningkatan $21,62 \%$ dari tahun 2017 sampai 2018. (Dirjen Perikanan Budidaya KKP, 2018). Sedangkan di Kabupaten Jepara berdasarkan data dari BPS yang diupdate terakhir tahun 2018 pada data produksi perikanan budidaya tahun 2016 sebesar $39.512,32$ ton di mana budidaya laut sebanyak $22.784,79$ ton, tambak $15.897,89$ ton, kolam 795,38 ton, KJA 23,37 ton dan kolam sawah 10,89 ton. Jumlah ini mengalamai penurunan tahun 2017 yaitu budidaya laut sebesar $27.201,15$ ton, produksi tambak $1.371,30$ ton dan produksi kolam 546,35 ton. Khusus produksi perikanan tambak mengalami penurunan yang cukup signifikan. Upaya peningkatan produksi sektor perikanan budidaya diupayakan dengan melakukan intensifikasi pengelolaan budidaya tambak. Upaya yang ditekankan adalah optimalisasi penggunaan media air laut yang sesuai dengan peruntukannya. Sebagaimana Poernomo (1992) menjelaskan bahwa masalah utama usaha perikanan budidaya tambak adalah kurang tepatnya menentukan lokasi budidaya yang berakibat terjadinya peningkatan cost production and operational, juga timbulnya masalah lingkungan. Penelitian ini bertujuan untuk memberikan informasi tentang parameter oksigen terlarut di sepanjang pantai Kabupaten Jepara untuk mendukung optimalisasi pengelolaan air laut sebagai media budidaya.

\section{METODOLOGI}

Metode penelitian yang digunakan adalah survey. Lokasi pengukuran dilakukan di sepanjang pantai Kabupaten Jepara berjumlah 10 titik dengan sebaran stasiun pengamatan sebagaimana dalam Gambar 1 dan keterangan lokasi perairan sebagaimana Tabel 1. Jarak antar titik pengamatan sekitar $700 \mathrm{~m}$ dan jarak dari pantai sekitar $500 \mathrm{~m}$. Pengukuran terhadap parameter kadar oksigen terlarut dan suhu secara insitu dilakukan pada bulan Juni 2019. Peralatan yang digunakan adalah DO-meter dan GPS. Pengulangan terhadap pengukuran oksigen terlarut dan suhu dilakukan sebanyak 3 kali dengan lokasi yang berdekatan dalam satu titik. Data yang didapatkan kemudian dianalisa secara kualitatif dengan membandingkan pada referensi daya dukung air laut untuk budidaya perairan khususnya tambak. Data DO yang diperoleh kemudian dibuatkan dalam bentuk peta tematik menggunakan program Arc-GIS 10.0. 


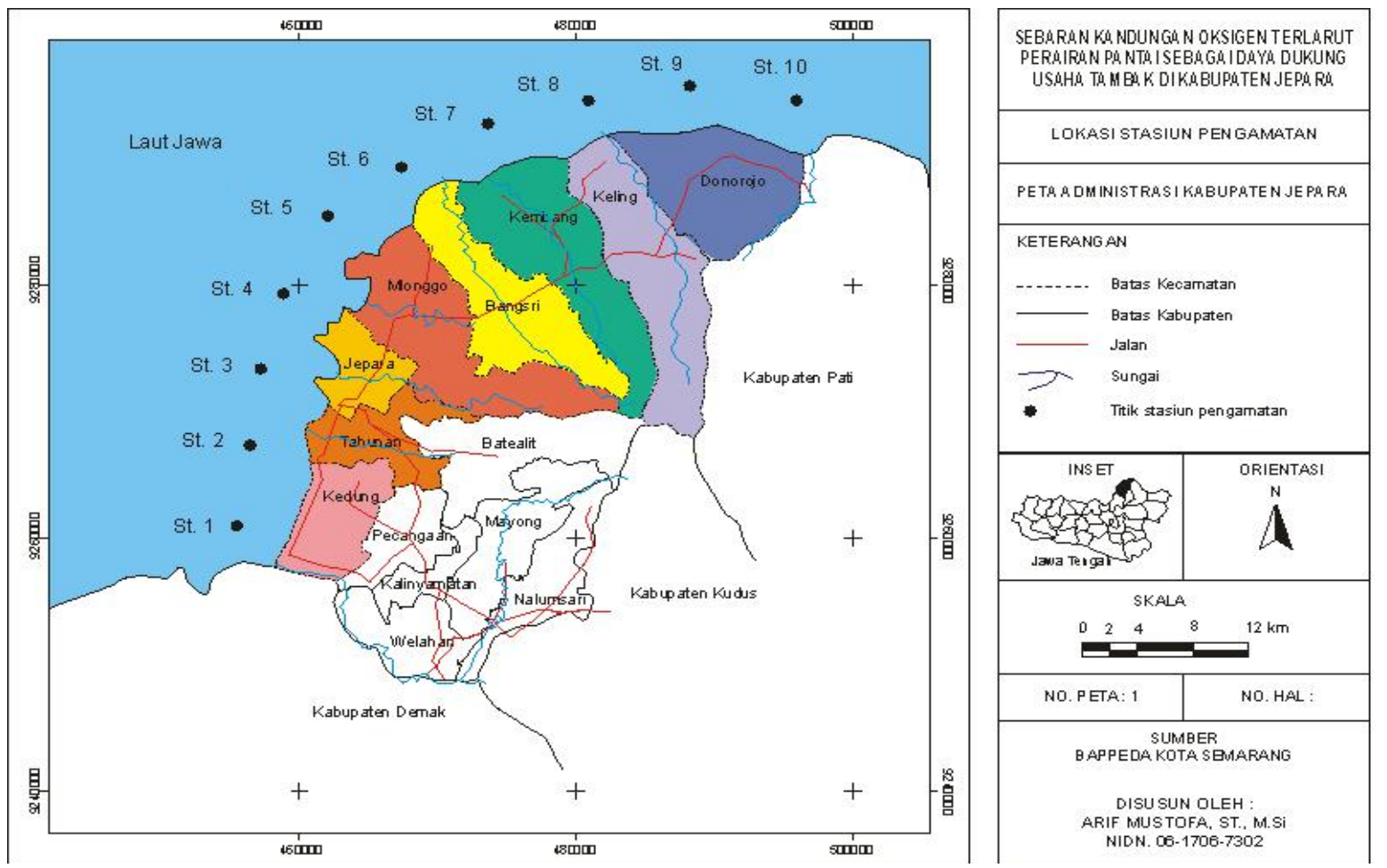

Gambar 1. Titik stasiun pengamatan di sepanjang pantai Kabupaten Jepara

Tabel 1. Lokasi perairan sesuai titik stasiun pengamatan

\begin{tabular}{|c|l|l|}
\hline St. & \multicolumn{1}{|c|}{ Koordinat } & \multicolumn{1}{c|}{ Keterangan } \\
\hline 1 & $-6.671167,110.599904$ & Perairan Pantai Desa Kedungmalang, Kec. Kedung \\
\hline 2 & $-6.620356,110.615181$ & Perairan Pantai Desa Semat, Kecamatan Tahunan \\
\hline 3 & $-6.572779,110.633034$ & Perairan Pantai Pulau Panjang, Kecamatan Jepara \\
\hline 4 & $-6.532191,110.646767$ & Perairan Pantai Desa Bandengan, Kecamatan Jepara \\
\hline 5 & $-6.457997,110.684533$ & Perairan Pantai Desa Mororejo, Kecamatan Mlonggo \\
\hline 6 & $-6.425076,110.748219$ & Perairan Pantai Kecamatan Bangsri \\
\hline 7 & $-6.406823,110.804696$ & Perairan Pantai Kecamatan Kembang \\
\hline 8 & $-6.388399,110.865120$ & Perairan Pantai Kecamatan Keling \\
\hline 9 & $-6.388740,110.918850$ & Perairan Pantai Kecamatan Donorojo sebelah barat \\
\hline 10 & $-6.395393,110.962109$ & Perairan Pantai Kecamatan Donorojo sebelah timur \\
\hline
\end{tabular}

\section{HASIL DAN PEMBAHASAN}

Hasil pengukuran terhadap kadar DO dan suhu di sepanjang pantai Kabupaten Jepara sebagaimana dalam Tabel 2.

Tabel 2. Kadar oksigen terlarut dan suhu di sepanjang pantai Kabupaten Jepara

\begin{tabular}{|c|c|c|c|}
\hline St. & Koordinat & $\begin{array}{c}\text { DO } \\
(\mathrm{mg} / \mathrm{l})\end{array}$ & $\begin{array}{c}\text { Suhu } \\
\left({ }^{\circ} \mathrm{C}\right)\end{array}$ \\
\hline 1 & $-6.671167,110.599904$ & 5,1 & 28,0 \\
\hline 2 & $-6.620356,110.615181$ & 5,1 & 27,8 \\
\hline 3 & $-6.572779,110.633034$ & 4,9 & 27,9 \\
\hline 4 & $-6.532191,110.646767$ & 4,9 & 27,9 \\
\hline 5 & $-6.457997,110.684533$ & 4,7 & 28,4 \\
\hline 6 & $-6.425076,110.748219$ & 4,8 & 28,5 \\
\hline 7 & $-6.406823,110.804696$ & 5,2 & 27,9 \\
\hline 8 & $-6.388399,110.865120$ & 5,4 & 28,6 \\
\hline 9 & $-6.388740,110.918850$ & 5,1 & 27,9 \\
\hline 10 & $-6.395393,110.962109$ & 5,1 & 28,0 \\
\hline
\end{tabular}

Data dalam Tabel 2 menunjukkan bahwa perairan pantai Kabupaten Jepara memiliki kandungan DO antara 4,7 mg/l - 5,4 $\mathrm{mg} / \mathrm{l}$. Kandungan DO terendah sebesar 4,7 $\mathrm{mg} / \mathrm{l}$ berada di titik stasiun 5 yaitu di Perairan Pantai Desa Mororejo, Kecamatan Mlonggo. Sedangkan kandungan DO tertinggi sebesar $5,4 \mathrm{mg} / \mathrm{l}$ berada di titik 8 yaitu di perairan pantai Kecamatan Keling. Secara jelas digambarkan dalam grafik sebagaimana Gambar 2. 


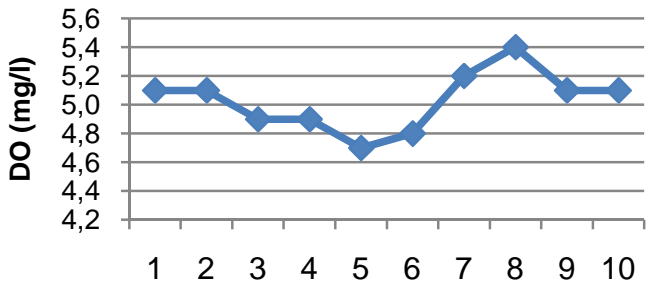

No. Stasiun

Gambar 2. Kandungan DO yang terukur tiap stasiun pengamatan

Berdasarkan modifikasi dari Sunyoto (1997) dalam Adibrata dkk (2013), Permen KP No. 75/PERMEN-KP/2016 serta Ratnawati dan Indrajaya (2012) di mana terdapat klasifikasi kesesuaian parameter kualitas air untuk digunakan sebagai air media budidaya. Klasifikasi tersebut sebagaimana Tabel 3.

Tabel 3. Kelas kesesuaian perairan berdasarkan nilai DO (mg/l)

\begin{tabular}{|c|c|c|}
\hline Kelas S1 & Kelas S2 & Kelas S3 \\
\hline $7-8$ & $5-<7$ & $<5$ \\
& $>8-10$ & $>10$ \\
\hline Keterangan : & Sangat sesuai (S1) \\
& Sesuai (S2) \\
& Tidak sesuai (S3)
\end{tabular}

Klasifikasi kandungan DO yang terukur berdasarkan Tabel 3 di atas adalah "sangat sesuai" jika nilai DO sebesar $7 \mathrm{mg} / \mathrm{l}-$ $8 \mathrm{mg} / \mathrm{l}$, "sesuai" jika nilai DO sebesar $5 \mathrm{mg} / \mathrm{l}$ $<7 \mathrm{mg} / \mathrm{l}$ dan $>8 \mathrm{mg} / \mathrm{l}-10 \mathrm{mg} / \mathrm{l}$ serta kelas "tidak sesuai" jika nilai DO sebesar $<5 \mathrm{mg} / \mathrm{l}$ dan $>10 \mathrm{mg} / \mathrm{l}$. Data hasil pengukuran parameter DO di pantai Kabupaten Jepara kemudian disesuaikan dengan referensi di atas. Berdasarkan Gambar 2 bahwa tidak ada nilai DO antara $7-8 \mathrm{mg} / \mathrm{l}$. Hal ini menunjukkan bahwa di sepanjang pantai Kabupaten Jepara nilai DO tidak berada dalam kelas "sangat sesuai". Gambar 2 juga menunjukkan beberapa lokasi perairan yang masuk dalam kelas "sesuai" yaitu nilai DO antara $5 \mathrm{mg} / \mathrm{l}-<7 \mathrm{mg} / \mathrm{l}$. Lokasi perairan tersebut adalah perairan pantai Kecamatan Kedung, Tahunan, Kembang, Keling dan Donorojo. Kelima wilayah perairan pantai ini memiliki kadar DO antara 5,1 mg/l - 5,4 mg/l. Sedangkan wilayah perairan lainnya yaitu Kecamatan Jepara, Mlonggo dan Bangsri memiliki nilai DO sebesar $4,7 \mathrm{mg}-4,9 \mathrm{mg} / \mathrm{l}$.
Angka ini masuk dalam kelas "tidak sesuai" karena berada di bawah $5 \mathrm{mg} / \mathrm{l}$.

Wilayah perairan pantai Kecamatan Kedung merupakan wilayah pesisir yang didominasi oleh areal pertambakan. Kondisi inipun sudah menjelaskan bahwa parameter kualitas air sudah mendukung untuk usaha tersebut. Hal ini dibuktikan dengan kegiatan perikanan tambak yang sudah dilakukan oleh masyarakat sejak lama. Usaha tambak yang mendominasi adalah tambak garam di musim kemarau dan akan diganti dengan tambak udang dan bandeng pada musim penghujan. Kondisi ini mengacu pada pendapat Ristiyani (2012) yang menganalisis kelayakan lahan pertambakan menggunakan variabel kelerengan lahan, tekstur tanah, $\mathrm{pH}$ tanah, penggunaan lahan, curah hujan, aksesbilotas dan jarak dari sungai dan laut. Berdasarkan variabel-variabel tersebut mengindikasikan lokasi tersebut layak untuk dijadikan pertambakan, sebagaimana lahan di Kecamatan Kedung.

Kadar DO perairan pantai Kecamatan Kedung sebesar $5,1 \mathrm{mg} / \mathrm{l}$ dengan suhu $28,0^{\circ} \mathrm{C}$ masuk dalam kelas sesuai untuk usaha budidaya perikanan tambak. Perairan pantai Kecamatan Tahunan memiliki karakteristik sebagai wilayah yang memiliki kawasan hutan mangrove di sebelah selatan dan kawasan pemukiman di sebelah utara. Perairan pantai Kecamatan Tahunan memiliki kandungan DO sebesar $5,1 \mathrm{mg} / \mathrm{l}$ dengan suhu perairan sebesar $27,8^{\circ} \mathrm{C}$. Kondisi ini menyebabkan perairan pantai Kecamatan Tahunan masuk dalam kelas sesuai untuk digunakan sebagai media budidaya perikanan tambak.

Kawasan perairan pantai di Kabupaten Jepara bagian utara yang masuk dalam kelas sesuai adalah perairan pantai Kecamatan Kembang. Kawasan pantai Kecamatan Kembang didominasi oleh tanah kosong dan beberapa tempat merupakan pemukiman nelayan. Nilai DO perairan pantai Kecamatan Kembang adalah 5,2 mg/l dengan suhu sebesar $27,9^{\circ} \mathrm{C}$. Kadar DO ini menunjukkan perairan pantai Kecamatan Kembang masuk dalam kelas sesuai sebagai media budidaya perikanan tambak. Demikian pula untuk wilayah perairan pantai Kecamatan Keling. Wilayah pesisir Kecamatan Keling didominasi oleh lahan kosong, pemukiman 
nelayan serta beberapa kawasan mangrove. Sebagaimana Bengen (2000) menjelaskan bahwa kawasan mangrove merupakan daerah penghasil bahan organik yang sangat produktif. Nilai DO perairan pantai Kecamatan Keling adalah sebesar $5,4 \mathrm{mg} / \mathrm{l}$ dengan suhu perairan sebesar $28,6^{\circ} \mathrm{C}$. Nilai DO di Kecamatan Kembang merupakan nilai tertinggi di sepanjang perairan pantai Kabupaten Jepara. Sesuai dengan pendapat Boyd (1982) bahwa kadar DO suatu perairan dipengaruhi oleh suhu, semakin meningkat suhu maka kandungan DO akan semakin besar. Demukian juga menurut Awanis et al. (2017), menjelaskan bahwa pengaruh DO terhadap hewan air budidaya adalah pada pertumbuhan dan efisiensi pakan. Konsentrasi DO rendah menyebabkan kultivan tidak akan makan dengan baik sehingga pertumbuhan terhambat dan rentan penyakit hingga kematian.

Nilai DO perairan pantai Kecamatan Keling menunjukkan masuk dalam kelas sesuai untuk digunakan sebagai media budidaya. Wilayah perairan pantai di Kabupaten Jepara yang paling utara adalah Kecamatan Donorojo. Kawasan pantai Kecamatan Donorojo didominasi oleh lahan kosong, kawasan pemukiman nelayan dan areal pertambakan udang dan ikan. Dengan adanya usaha tambak budidaya sudah menunjukkan bahwa kondisi perairan pantai cukup baik untuk mendukung usaha tambak milik masyarakat setempat. Nilai DO perairan Kecamatan Kembang adalah 5,1 mg/l dengan suhu sekitar $28^{\circ} \mathrm{C}$. Hal ini menunjukkan bahwa kondisi perairan pantai Kecamatan Donorojo masuk dalam kelas sesuai untuk usaha budidaya perikanan tambak, seperti yang telah dilakukan oleh masyarakat yaitu usaha tambak udang vaname dan ikan bandeng.

Nilai kandungan DO di sepanjang perairan pantai Kabupaten Jepara dibuat dalam bentuk peta tematik sebagaimana dalam Gambar 3.

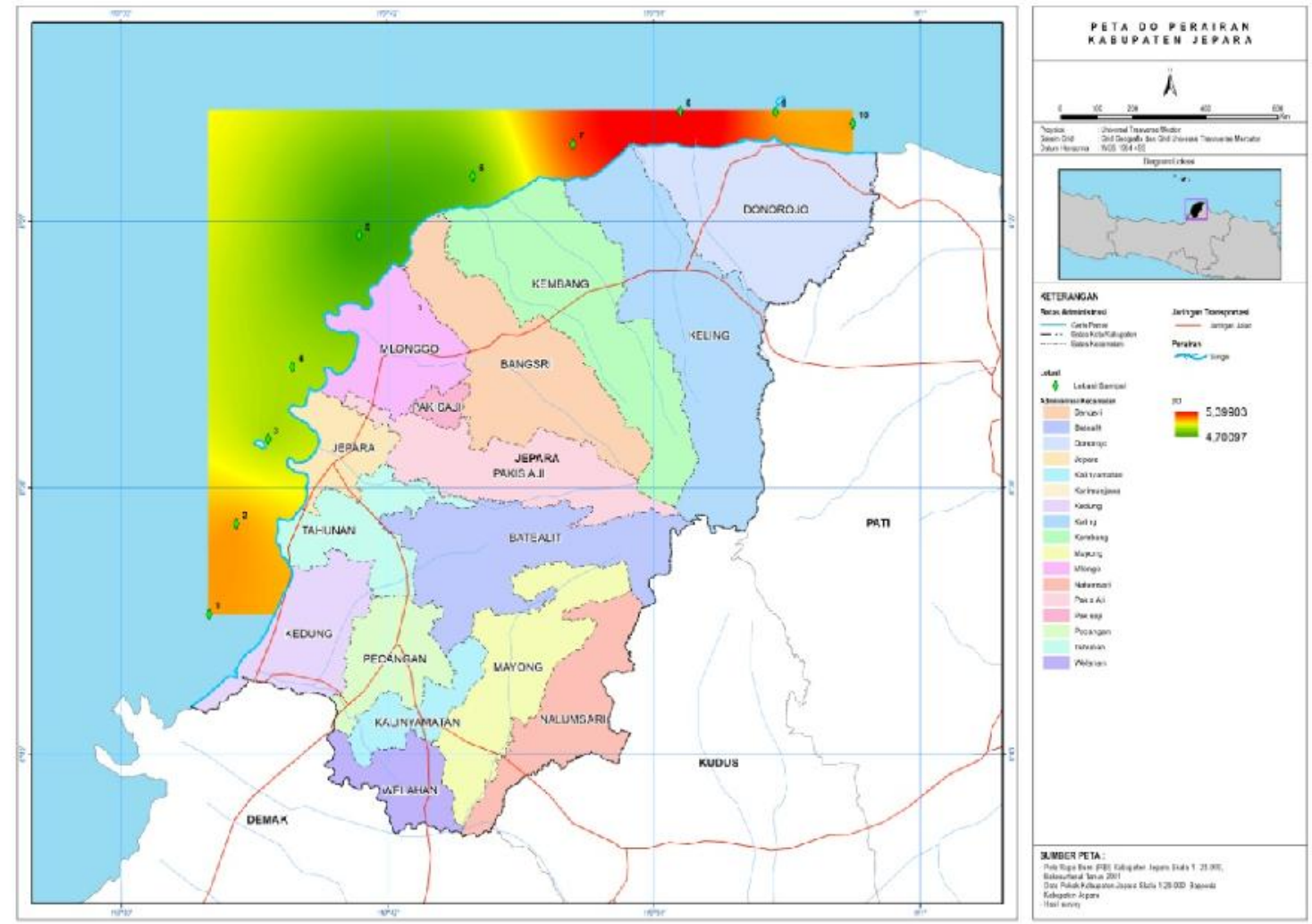

Gambar 3. Peta sebaran DO di perairan pantai Kabupaten Jepara

\section{SIMPULAN}

Berdasarkan analisa kandungan DO di sepanjang perairan pantai Kabupaten Jepara, perairan pantai Kecamatan Kedung, Tahunan,
Kembang, Keling dan Donorojo memiliki kadar DO antara $5,1 \mathrm{mg} / \mathrm{l}-5,4 \mathrm{mg} / \mathrm{l}$. Nilai ini menunjukkan kelas sesuai untuk mendukung kegiatan budidaya tambak. 


\section{DAFTAR PUSTAKA}

Adibrata, S., M. Mukhlis K. dan Fredinan Y. 2013. Daya Dukung Lingkungan Untuk Budidaya Kerapu (Famili Serranidae) di Perairan Pulau Pongok Kabupaten Bangka Selatan. Jurnal Pesisir dan Pulau-Pulau Kecil. Vo. 2 No. 1, Juli 2013 : 43-58.

Aliyah, R. S. 2013. Evaluasi Kondisi Lingkungan Perairan Pantai Utara Karawang Untuk Mendukung Pengembangan Budidaya Perikanan. J. Tek. Ling. Vol. 14 No. 2 Juli 2013. Hal. 67-73

Awanis, A.A., S. B. Prayitno dan V. E. Herawati. 2017. Kajian Kesesuaian Lahan Tambak Udang Vaname dengan Menggunakan Sistem Informasi Geografis di Desa Wonorejo Kecamatan Kaliwungu, Kendal, Jawa Tengah. Buletun Oseanografi Marina, Vo. 6 No. 2, Oktober 2017: 102-109.

Bengen, D.G. 2000. Ekosistem Dan Sumber Daya Alam Pesisir. Pusat Sumber Daya. Pesisir dan Lautan, Institut Pertanian Bogor. Bogor.

Boyd, C.E. 1982. Water Quality Management for Pond Fish Culture. Elsevier, Amsterdam, 318

Mardiatno, D., B. Susilo dan E.T W. Mei. 2018. Potensi Sumberdaya Pesisir Kabupaten Jepara. Gadjah Mada University Press. Yogyakarta.

Odum, E.P. 1971. Fundamental of Ecology. $3^{\text {rd }}$ Edition, W.B. Saunders, Philadelphia.

Peraturan Menteri Kelautan dan Perikanan RI No. 75/PERMEN-KP/2016 tentang Pedoman Umum Pembesaran Udang Windu (Penaeus monodon) dan Udang Vaname (Litopenaeus vannamei).

Poernomo, A. 1992. Pemilihan Lokasi Tambak Udang Berwawasan Lingkungan. Pusat Penelitian dan Pengembangan Perikanan Badan Penelitian dan Pengembangan Pertanian. Jakarta.

Ratnawati, E dan A. Indrajaya A. 2012. Daya Dukung Lingkungan Tambak di Kecamatan Pulau Derawan dan
Sambaliung, Kabupaten Berau, Provinsi Kalimantan Timur. Jurnal IImiah Perikanan dan Kelautan. Vo. 4 No. 2, November $2012: 175-185$.

Ristiyani, D. 2012. Evaluasi Kesesuaian Lahan Untuk Budidaya Perikanan Tambak Di Pesisir Kendal. Jurnal Geo Image 1 (1) 2012 : 12-18.

Wardoyo, S.T.H. 1981. Kriteria Kualitas Air untuk Keperluan Pertanian dan Perikanan. Makalah Training AMDAL, Kerjasama PPLH-UNDEP-PUSDL $\neg P S L$, 19-31, Januari, 1981, Bogor. 